\title{
A bela morte do herói: corpo, câncer e medicalização em narrativas de quadrinhos
}

\author{
The hero's beautiful death: body, cancer and medicalization in comics" \\ narratives
}

\section{La bella muerte del héroe: cuerpo, cáncer y medicalización en narrativas de cómics}

Marcos Fábio Medeiros Vieira ${ }^{1,2, a}$

marcosfvieira@yahoo.com.br | http://orcid.org/o0oo-0002-5966-8596

Denise da Costa Oliveira Siqueira ${ }^{1, b}$

dcos@uerj.br | http://orcid.org/0000-0001-7501-7390

${ }^{1}$ Universidade do Estado do Rio de Janeiro, Programa de Pós-Graduação em Comunicação. Rio de Janeiro, RJ, Brasil.

${ }^{2}$ Instituto Nacional de Câncer José Alencar Gomes da Silva. Rio de Janeiro, RJ, Brasil.

a Mestrado em Comunicação pela Universidade do Estado do Rio de Janeiro.

b Doutorado em Ciências da Comunicação pela Universidade de São Paulo.

\section{RESUMO}

Neste artigo estudamos a fabricação do imaginário social sobre o câncer representado em histórias em quadrinhos de super-heróis. O objetivo é discutir a emergência do câncer na cultura das mídias. Instiganos a questão da representação do imperativo médico como produtor de saberes e práticas de controle dos corpos nas narrativas ficcionais e na tragédia do herói. O recorte metodológico recai sobre o estudo da trajetória de dois personagens de quadrinhos da editora norte-americana Marvel Comics: a Poderosa Thor e o Capitão Marvel. Abordamos, ainda, a influência do modelo médico de pensamento nas sociedades ocidentais. Para tal, recorremos a um referencial da comunicação e a leituras nos campos da sociologia e da antropologia. Por meio de pesquisa documental e da leitura de narrativas espetaculares sobre o herói e o câncer, relacionamos mitos, imaginários, corpo e emoções.

Palavras-chave: Histórias em quadrinhos; Medicalização; Midiatização; Corpo; Câncer.

\section{ABSTRACT}

In this article, we study the fabrication of the social imaginary about cancer represented in superhero comics. The goal is to discuss the emergence of cancer in media culture. It raises the question of the medical imperative as a producer of knowledge and practices of body control in fictional narratives and in the hero's tragedy. The methodological approach lies in the study of the trajectory of two comic characters from the 
US Marvel Comics Publishing House: Mighty Thor and Captain Marvel. We also approach the influence of the medical model of thought in western societies. To this end, we use a framework of communication and readings in the fields of sociology and anthropology. Through documentary research and reading of spectacular narratives about the hero and cancer, we relate issues involving myths, the imaginary, the body and emotions.

Keywords: Comics; Medicalization; Mediatization; Body; Cancer.

\section{RESUMEN}

En este artículo, estudiamos la fabricación del imaginario social sobre el cáncer representado en los cómics de superhéroes. El objetivo es discutir la aparición del cáncer en la cultura de los medios. Plantea la cuestión de la representación del imperativo médico como productor de conocimiento y prácticas de control corporal en las narraciones ficticias y en la tragedia del héroe. El enfoque metodológico está en el estudio de la trayectoria de dos personajes de la editorial estadounidense Marvel Comics: Poderosa Thor y Capitán Marvel. También abordamos la influencia del modelo médico del pensamiento en las sociedades occidentales. Para este fin, utilizamos un marco de comunicación y lecturas en los campos de la sociología y la antropología. A través de la investigación documental y la lectura de narraciones espectaculares sobre el héroe y el cáncer, relacionamos los mitos, lo imaginario, el cuerpo y las emociones.

Palabras clave: Cómics; Medicalización; Mediatización; Cuerpo; Cáncer.

Contribuição dos autores:

Concepção e desenho do estudo: Marcos Fábio Medeiros Vieira.

Aquisição, análise ou interpretação dos dados: Marcos Fábio Medeiros Vieira.

Redação do manuscrito: Marcos Fábio Medeiros Vieira e Denise da Costa Oliveira Siqueira.

Revisão crítica do conteúdo intelectual: Denise da Costa Oliveira Siqueira.

Declaração de conflito de interesses: não há

Fontes de financiamento: Coordenação de Aperfeiçoamento de Pessoal de Nível Superior (Capes), Conselho Nacional de Desenvolvimento Científico e Tecnológico (CNPq), Fundação de Amparo à Pesquisa do Estado do Rio de Janeiro (Faperj).

Considerações éticas: não há

Agradecimentos/Contribuições adicionais: não há.

Histórico do artigo: submetido: 01 jan. 2020 | aceito: 14 out. 2020 | publicado: 22 mar. 2020.

Apresentação anterior: Uma versão bastante preliminar deste artigo foi apresentada no GT Corpo, identidades e comunicação do XV Póscom da PUC-Rio.

Licença CC BY-NC atribuição não comercial. Com essa licença é permitido acessar, baixar (download), copiar, imprimir, compartilhar, reutilizar e distribuir os artigos, desde que para uso não comercial e com a citação da fonte, conferindo os devidos créditos de autoria e menção à Reciis. Nesses casos, nenhuma permissão é necessária por parte dos autores ou dos editores. 


\section{INTRODUÇÃO}

Inspirado no deus do trovão da mitologia nórdica, o personagem de histórias em quadrinhos Thor tem suas aventuras publicadas pela editora Marvel Comics desde 1952, quando fez sua primeira aparição na revista Journey into Mystery (1952). Como seu homônimo mitológico, o herói carrega o martelo místico Mjolnir, que lhe confere habilidades sobre-humanas, força descomunal, capacidade de voar e de controlar tempestades. Forjado a mando de Odin, pai de Thor e senhor dos deuses nórdicos, o martelo traz um feitiço que dá a quem o tem a imortalidade e os poderes do deus do trovão. Segundo a inscrição na lateral da arma, "Whosoever holds this hammer, if he be worthy, possesses the power of... Thor" (LEE; LIEBER; KIRBY, 1952, p. 5).

Na minissérie em quadrinhos Original Sin (Pecado original) (AARON; DEODATO, 2014), publicada nos Estados Unidos em 2014, Thor teve conhecimento de um segredo que o fez sentir-se indigno e, portanto, incapaz de erguer o martelo místico. A médica Jane Foster, com quem Thor tivera um romance, encontrou Mjolnir e, sendo considerada digna, recebeu os poderes do deus do trovão. Embora não tenha sido a primeira personagem a erguer o martelo, Jane assumiria, nesse momento, uma especificidade: estar acometida por um câncer de mama. Jane é a primeira mulher nos quadrinhos da editora Marvel a empunhar a arma mística, que já foi usada por personagens como o Capitão América, o alienígena Bill Raio Beta e o vilão Loki, irmão adotivo e adversário de Thor.

Essa não foi a primeira vez que a poderosa indústria de quadrinhos americana criou um super-herói acometido por um câncer. Na década de 1980, outro herói teve sua história marcada pela doença. A narrativa sobre Capitão Marvel incluiu sua morte, em 1982, levando a representação da doença para as histórias de super-heróis. Embora a história de A morte do Capitão Marvel não tenha sido levada ao cinema, a Marvel Studios anunciou para 2022 a adaptação narrativa da Poderosa Thor no filme Thor: love and thunder. Apesar de ainda não estar confirmada no filme, a jornada de Foster contra o câncer tem sido abordada na imprensa com expectativai.

A primeira vez em que a Marvel mostrou uma personagem com câncer no cinema foi em Guardiões da galáxia, filme de 2014. No início do filme, a mãe do protagonista, o personagem Senhor das Estrelas, morre de câncer, tendo sido exposta a radiações pelo pai do herói, o alienígena de poderes cósmicos Ego, o Planeta Vivo. Mesmo mantendo um tom de comédia, o filme abordou de forma sensível a doença e a morte da personagem, um dos momentos mais dramáticos da filmografia da Marvel e que colaborou para a construção simbólica do personagem Senhor das Estrelas. A conexão emocional com a mãe é representada na trilha sonora do filme, que o personagem carrega consigo em um walkman com fitas gravadas pela mãe e deixadas como lembrança para ele. A narrativa do câncer, embora breve, serve de ligação entre passado e presente e para a construção dos afetos entre os personagens.

A presença do câncer como mediador de processos emocionais em narrativas de ficção, mesmo em uma mídia voltada para o entretenimento e para narrativas de ação como os quadrinhos, mostra a relevância que a doença adquiriu desde estudos como os de Susan Sontag (2007).

Partindo de uma leitura dessas duas narrativas midiáticas, este artigo visa compreender as narrativas ficcionais sobre a experiência do câncer e suas relações com a construção social das emoções e do imaginário mitológico sobre a doença. Buscamos entender como a medicalização do cotidiano e o saber médico se articulam com a produção de narrativas mítico-midiáticas e as práticas de controle, disciplinando corpos e alterando formas de estar no mundo. Em termos metodológicos, para servir de base empírica para a análise, selecionamos cinco números de Mighty Thor, publicadas nos Estados Unidos entre 2015 e 2018 (e

i Em 2019, Natalie Portman, que interpreta no cinema a personagem Jane Foster, respondeu à revista Variety (2019) não saber se o câncer seria abordado no filme Thor: love and thunder. Um ano depois, Portman menciona, em entrevista ao Yahoo! Movies, que a personagem “[...] está passando pelo tratamento do câncer e é uma super-heroína no tempo livre" (NATALIE..., 2020). 
republicadas, entre 2017 e 2018 em cinco volumes encadernados), e a graphic novel A morte do Capitão Marvel, publicada originalmente em 1982.

No artigo discutimos o papel da cultura das mídias na construção de significações acerca da ciência e as tensões entre os saberes biomédico e mítico-religioso. No centro da narrativa, o corpo, lugar onde se desenvolve o drama dos heróis e onde se manifestam emoções e significações simbólicas. O corpo é também o instrumento por meio do qual o homem interage com o mundo e a partir do qual produz saberes sobre a sociedade.

Em termos de referencial teórico, recorremos às visões de Mauss (2017), Foucault (2018), Le Breton (2004; 2013), Siqueira (2008; 2015), e Siqueira e Moreira (2019) sobre o corpo e as emoções; e de Campbell (2007), Vernant (1978) e Morin (2009), sobre o mito e a tragédia. Abordamos, ainda, as noções de medicalização a partir de autores como Lowenberg e Davis (1994), Conrad (1992), Rose (2007); e de saúde, doença e risco nas perspectivas de Lupton (2005), Sontag (2007), Douglas (1991), Zola (1972) e Lerner (2016). Relacionamos tais conceitos à ideia de controle do corpo e aos ideais de imortalidade, seja na negação ou na busca da bela morte, entendida por Vernant (1978) como a morte que levaria o guerreiro ao estado de glória eterna. Para o autor, o sacrifício do herói representaria o ápice da honra, elevando-o a uma excelência que não precisaria mais ser posta à prova pelo confronto: "ela se realiza de vez e para sempre no feito que põe fim à vida do herói” (1978, p. 32). Diante dessa perspectiva, entendemos que a narrativa trágica do câncer aproxima os protagonistas do 'herói caído', cujo sacrifício teria o poder de expiar as culpas e revesti-lo de glória póstuma, conferindo-lhe, por fim, a fama e a imortalidade, livre da decadência e dos sofrimentos do corpo.

A questão que nos instiga diz respeito à representação do câncer nas histórias em quadrinhos de super-heróis, forma de entretenimento popular de produção massiva na qual ciência, mito e tragédia mostram-se elementos de identificação e de produção de valores morais. A emergência da doença no imaginário fantástico dos quadrinhos, cuja influência se estende, atualmente, ao cinema e à TV, encontrando também repercussão na mídia jornalística e nas redes sociais, tanto a aproxima da existência cotidiana quanto reforça a importância narrativa da bela morte, reafirmando seu caráter agonístico e reforçando valores morais comuns à jornada do herói.

Localizamos nossa abordagem do imaginário na sociologia compreensiva de Maffesoli, que difere de uma tradição romântica que buscava opor o real, ou verdadeiro, ao imaginário. Para o autor, o imaginário seria o "algo mais" (2008, p. 75), o caráter transcendente, imponderável ou o "estado de espírito que caracteriza um povo" (2008, p. 75). É por meio do imaginário, segundo Maffesoli, que se estabelecem os vínculos sociais; cimento da vida social, como define o autor, o imaginário ultrapassa o indivíduo e impregna o coletivo, é força social de ordem espiritual, que contempla "o onírico, o lúdico, a fantasia, o imaginativo, o afetivo, o não racional, o irracional, os sonhos, enfim, as construções mentais potencializadoras das chamadas práticas" (2008, p. 76-77). A partir dessa perspectiva, propomos pensar um imaginário dos quadrinhos não como algo fora do real, mas como sua face onírica, imaginativa, por meio da qual o real ultrapassaria o racional e beberia da mesma fonte dos sonhos, dos heróis e dos mitos.

\section{CORPO, MEDICALIZAÇÃO E O IMPERATIVO DA SAÚDE}

A fim de compreender as construções simbólicas sobre o câncer nos quadrinhos de super-heróis, partiremos de uma leitura sobre o corpo, entendendo-o como meio de contato do homem com o mundo. No corpo experimentamos afetos, prazeres, dores, sofrimentos, medo e angústia.

Para Marcel Mauss (2017), o corpo seria o primeiro e "mais natural" (p. 428) instrumento do homem. Na visão do sociólogo, é por meio de técnicas corporais que os homens, de sociedade a sociedade, saberiam 
servir-se de seus corpos. Nessa perspectiva, o corpo, assim como seus usos, adquire espaço privilegiado na cultura e nos saberes sobre o homem e suas formas de estar no mundo.

O corpo comunica, é meio e mediador da comunicação, como observa Siqueira (2015). Para a autora, o sentido sobre o corpo não é dado, mas culturalmente construído, assim como a expressão das emoções. O corpo seria, portanto, meio para a construção de discursos e sentidos que variam de sociedade para sociedade.

Embora hoje ocupe espaço privilegiado nas discussões sobre saúde e doença, o corpo nem sempre foi objeto das ciências. Pode-se dizer que o corpo começa a ser inventado a partir das necessidades de saberes em emergência, como a medicina, que teve, a partir do século XVIII, papel importante nas sociedades ocidentais. Segundo Augusto Bozz (2016), “o corpo não 'apareceu' simplesmente na medicina, mas se tornou objeto problemático, estranho e pouco familiar em uma determinada região do saber” (p. 36).

Na visão de Foucault (2018), foi com o advento da Modernidade que o corpo se tornou objeto de estudo das ciências biológicas e alvo de cuidados, de um modo quase médico. A nova ênfase no corpo da sociedade, e não no do monarca, viria acompanhada de receitas e terapêuticas cujo objetivo seria o controle das doenças e, portanto, dos corpos dos doentes, dos pobres, dos contagiosos e dos delinquentes.

Foucault discorre sobre o controle e a vigilância investidos de forma densa, rígida e meticulosa sobre os corpos, "daí esses terríveis regimes disciplinares que se encontram nas escolas, nos hospitais, nas casernas, nas oficinas, nas cidades, nos edifícios, nas famílias" (FOUCAULT, 2018, p. 237). O corpo, especialmente o dos pobres, deveria ser não só beneficiado pelos serviços de assistência, mas também submetido a vários controles médicos, a fim de se manter produtivo e evitar a propagação de doenças.

Com o avanço das tecnologias médicas e do controle de doenças, práticas cotidianas passaram a ser associadas à ideia de risco e, por conseguinte, aos valores morais e à culpa. Na visão de Mary Douglas (1991), o controle do corpo é uma expressão do controle social, estando associado à ideia de "poluição social" (p. 91) e às transgressões morais e culturais. As ideias de presságio ou de culpa estariam ligadas a escolhas morais e a mecanismos de culpabilização, a partir dos quais seria preciso sempre apontar um 'culpado'.

A ideia de culpa, no entanto, vem sendo substituída por outra noção. Lupton (2005) observa, em sociedades secularizadas, a substituição do conceito de culpa pelo de risco, algo característico do discurso moderno, sanitarizado. Nesse sentido, Irving Zola (1972) acrescenta a inclusão de práticas cotidianas no hall dos riscos para a saúde e a importância conferida à saúde como valor social, assim como seu controle restrito à profissão médica.

From sex to food, from aspirins to clothes, from driving your car to riding the surf, it seems that under certain conditions, or in combination with certain other substances or activities or if done too much or too little, virtually anything can lead to certain medical problems. In short, I at least have finally been convinced that living is injurious to health. This remark is not meant as facetiously as it may sound. But rather every aspect of our daily life has in it elements of risk to health (ZOLA, 1972, p. 498).

A ideia de risco, contida em atividades do dia a dia, contribui para legitimar o poder das ciências médicas sobre a vida das sociedades, levando à classificação de comportamentos e práticas corporais como comer, dormir, caminhar, banhar-se e fazer sexo como fatores de risco ou de prevenção de doenças.

Para Nikolas Rose (2007), as práticas médicas desempenham papel definidor na concepção das sociedades, modificando a própria forma do homem contemporâneo. Alterações no ambiente, nas interações e nos usos dos espaços urbanos e nas formas de alimentação, higiene, locais de vida e de trabalho, motivados pela autoridade médica, modificaram não só os hábitos, mas também a aparência física, a longevidade e morbidade. Para o autor, a autoridade médica participa das formas de governo, não só ao diagnosticar e tratar de doenças, mas ao instituir políticas de cuidado e de promoção da saúde que modificam as práticas 
corporais e de saúde e os hábitos individuais e coletivos. A medicina estaria diretamente relacionada à maneira como experimentamos e damos sentido ao mundo.

Nos discursos de media como revistas de moda, sites e blogs, e com o reforço das mídias sociais, as tecnologias de dominação do corpo, seja para fins estéticos ou para controle de doenças, afirmaram-se como meios de produção de identidades e de utopias do corpo. Tais discursos apontam para a necessidade de corrigir o corpo ou de adequá-lo a uma identidade cambiante, em construção. O corpo seria hoje "remanejado por motivos terapêuticos que praticamente não levantam objeções, mas também por motivos de conveniência pessoal, às vezes ainda para perseguir uma utopia técnica de purificação do homem, de retificação de seu ser no mundo. O corpo encarna a parte ruim, o rascunho a ser corrigido" (LE BRETON, 2013, p. 16).

Na visão de Le Breton, o corpo, diante da crença na onipotência da ciência - supostamente capaz de resolver sofrimentos e fragilidades, tornando-o uma espécie de máquina cujas partes podem ser dissecadas, substituídas ou aperfeiçoadas -, "deixa de fazer sentido, 'funciona' ou manifesta uma 'pane', é obstáculo" (2013, p. 74). Torna-se assim alter ego, um duplo, um outro de si mesmo, sujeito a modificações de todos os tipos e suporte de identidades maleáveis, provisórias. A medicina, segundo Le Breton (2013), ultrapassaria os limites do cuidado e buscaria, por meio de intervenções, controlar a própria genética do corpo, dominar a vida e, por que não, a morte, tornando o corpo mero objeto da ciência. Na visão de adeptos de movimentos como o pós-humanismo, como observa o autor, o corpo, lugar de morte e doenças, seria alvo de suspeitas do qual a humanidade deveria se liberar em direção a um futuro no qual a mente pudesse, enfim, trocar de pele quantas vezes fossem necessárias, em busca da imortalidade.

É nessa tensão entre o corpo cotidiano e o corpo imaginado, representada em narrativas contemporâneas, como as dos quadrinhos de super-heróis, que buscamos compreender a construção de sentidos e uma certa mitificação do corpo na experiência do câncer. O imaginário de luta e superação que serve de pano de fundo para essas narrativas aproxima seus personagens de heróis cujas trajetórias servem de inspiração para leitores ou seguidores. Como observa Campbell: "em todas as épocas e sob todas as circunstâncias, os mitos humanos têm florescido; da mesma forma, esses mitos têm sido a viva inspiração de todos os demais produtos possíveis das atividades do corpo e da mente humanos" (2007, p. 15).

\section{MITO E CIÊNCIA NOS QUADRINHOS}

A narrativa mítica e heroica consiste em manifestação simbólica de crenças e condutas morais que influenciam o viver cotidiano, bem como as formas de interpretar o mundo, o corpo e a trajetória dos indivíduos ao longo da existência. A narrativa de câncer aproxima o doente de câncer da figura do herói que parte em busca de transformação ou de renascimento, pois "apenas o nascimento pode conquistar a morte - nascimento não da coisa antiga, mas de algo novo" (CAMPBELL, 2007, p. 26). A jornada do herói, nesse caso, é a superação do antigo para o surgimento de um novo sujeito, renovado pelo sofrimento em vida ou pela morte gloriosa, que pode se dar de forma metafórica, na destruição do antigo eu e substituição por um mais sábio e dignificado, ou material, na morte do corpo, que o conduz à transcendência em forma de mito. Mesmo nos casos em que o doente perece em decorrência do câncer, sua imagem é imortalizada na do herói que 'tombou' ante um inimigo terrível mas que, com isso, reafirma o caráter nobre de guerreiro (CAMPBELL, 2007).

As construções em torno da ciência e da medicina nas histórias em quadrinhos (HQs) envolvem tensões entre razão e mito, conflitos morais e modelos estereotipados, simulados, de bem e mal. Conrad (1992) destaca a "perturbadora e horripilante" (p. 217) colaboração entre médicos e nazistas, na Alemanha, sob o pretexto de "erradicar defeitos genéticos" (1992, p. 27). Longe de ser uma visão unicamente pessimista 
da colaboração de médicos em relação às instituições de poder, o exemplo do autor procura ressaltar os dilemas morais do uso do saber médico e suas consequências para as sociedades.

Mesmo no imaginário dos comics, é perceptível a interferência do saber médico, na reprodução de estereótipos do 'cientista maluco' ou do 'médico-deus'. Essas construções, que não se referem a qualquer instância 'real', criam uma atmosfera mítica em torno da doença e legitimam a autoridade do médico e do profissional da ciência, como veremos no contexto das narrativas de Mar-Vell e Jane Foster. Para Campbell:

O médico é o moderno mestre do reino do mito, o guardião da sabedoria a respeito de todos os caminhos secretos e fórmulas poderosas. Seu papel equivale precisamente ao do Velho Sábio, presença constante nos mitos e contos de fadas, cujas palavras ajudam o herói nas provas e terrores da fantástica aventura. É ele que aparece e indica a brilhante espada mágica que matará o dragão-terror; ele conta sobre a noiva que espera e sobre o castelo dos mil tesouros, aplica o bálsamo curativo nas feridas quase fatais e, por fim, leva o conquistador de volta ao mundo da vida normal após a grande aventura na noite encantada (2007, p. 19-20).

A partir da ideia de medicalização do cotidiano, veremos como o saber médico e a construção simbólica do câncer em narrativas contemporâneas influenciam a trajetória de vida e morte dos doentes e sua relação com a figura do herói. As histórias fantásticas, por meio das quais o leitor entra em contato com representações de dilemas e afetos do homem comum, servem não como um imperativo inevitável, mas como fio condutor, assim como no mito de Ariadne, cuja "matéria-prima para o seu fio de linho foi colhida nos campos da imaginação humana” (CAMPBELL, 2007, p. 31). É na imaginação humana que a 'afetuosa virgem' encontra o material para conduzir o herói, Teseu, pelo labirinto do Minotauro. Da mesma forma, é no imaginário que os quadrinhos encontram a matéria-prima para a construção de narrativas.

\section{A MORTE DO CAPITÃO MARVEL}

A publicização do câncer na mídia se intensificou, segundo Lerner (2016), com o surgimento de um novo contexto sanitário, influenciado pelo aparecimento da Aids e pelo aumento da incidência de doenças crônico-degenerativas. Anteriormente, os debates em torno da saúde pública, por volta dos anos 1970, haviam trazido maior visibilidade à doença, que ganhou espaço nos meios de comunicação de massa, emergindo como 'assunto de interesse público'.

Além da crescente presença do câncer nos debates da imprensa, a partir da década de 1980, a doença também emerge como tema em outras mídias, inclusive as voltadas para o público jovem, como as histórias em quadrinhos. O lançamento, em 1982, de A morte do Capitão Marvel trouxe aos quadrinhos uma abordagem inovadora, ao mostrar pela primeira vez um super-herói que, após diversas batalhas contra inimigos superpoderosos, sucumbe ao câncer.

Na história, o alienígena Mar-Vell, nascido de uma raça hostil, os Krees, é enviado à Terra em missão de espionagem e conquista. No entanto, ao aprender sobre a humanidade, acaba por desertar de seu povo e decide se tornar o protetor cósmico da Terra. Nas palavras do herói, "quanto mais aprendia sobre o planeta, mais repugnado ficava com a ideia de os tiranos Krees estragarem esse mundo adorável e escravizarem sua população indefesa" (STARLIN; ENGLEHART; MOENCH; BRODERICK, 2017, p. 66). Ao assumir a missão de proteger a Terra e seus habitantes, o herói tem seu nome, Mar-Vell, ressignificado para Capitão Marvel.

Em uma de suas aventuras, Mar-Vell salva a vida de milhares de inocentes da exposição a um gás venenoso, mas acaba exposto à substância, que anos depois lhe causa um câncer letal. Em um diálogo com um de seus aliados, o titã Mentor, Mar-Vell expressa suas emoções em relação à doença: “- Já estudei uma montanha de tomos médicos, procurando uma cura pro meu problema específico... e 'falhei'. Não pedi sua ajuda antes porque não fui capaz de expressar meu "medo"' (STARLIN; ENGLEHART; MOENCH; BRO- 
DERICK, 2017, p. 78). A resposta de Mentor complementa o caráter trágico do momento da revelação da doença: “- Posso compreender... é uma doença terrível. Em Titã, nós a chamamos de 'decomposição interna'. Vocês, Krees, batizaram de 'fim negro'. Os terráqueos chamam de 'câncer”' (STARLIN; ENGLEHART; MOENCH; BRODERICK, 2017, p. 78). Os nomes dados à doença reforçam a aura de fatalidade, servindo para a construção social do câncer como um destino terrível.

Para Rosenberg (1992), a doença tem início na percepção da manifestação física dos sintomas. Segundo o autor, a origem histórica da medicina estaria na busca dos enfermos por aconselhamento e explicação para seu infortúnio. Da mesma forma, um dos papéis da medicina residiria na função de dar nome à dor e ao desconforto do paciente: "[...] even a bad prognosis can be better than no prognosis at all; even a dangerous disease, if it is made familiar and understandable, can be emotionally more manageable than a mysterious and unpredictable one" (ROSENBERG, 1992. p. 310).

A essa ação de nomear a doença, o autor associou o conceito de enquadramento, por seu caráter explicativo. A doença, vista como experiência, cristalizada como uma entidade específica e manifesta em certos indivíduos, participaria do processo de estruturação social, como ator e mediador da vida social. A partir do diagnóstico, o paciente seria capaz de reconstituir sua trajetória anterior à doença, analisando os fatores que possivelmente levaram a ela, assim como redefinir sua vida a partir dela. O doente torna-se ator e autor de sua própria história. A narrativa do câncer, em seu aspecto de construção e reconstrução do eu, caracteriza-se como um devir: "we are always becoming" (ROSENBERG, 1992. p. 310).

A dramatização dos relatos sobre o câncer reproduz e legitima o imaginário trágico da doença nas sociedades ocidentais contemporâneas. A ideia de morte é representada em expressões como "marcha para a escuridão" (STARLIN; ENGLEHART; MOENCH; BRODERICK, 2017, p. 80) e em falas do herói carregadas de sentimentos de resignação, como "- Lutar contra uma doença terminal está um pouco fora do meu alcance. Sou um 'guerreiro', não um 'médico'.” (STARLIN; ENGLEHART; MOENCH; BRODERICK, 2017, p. 80) e "- Acho que minha hora finalmente chegou. Nunca esperei que fosse assim, mas estou aprendendo a conviver com isso." (STARLIN; ENGLEHART; MOENCH; BRODERICK, 2017, p. 80).

O sentimento de impotência diante da doença põe em questão a identidade de guerreiro, ao mesmo tempo em que confronta o herói com a própria mortalidade. Mesmo em um corpo superpoderoso, capaz de vencer inúmeras batalhas, Mar-Vell é confrontado com suas limitações. O corpo do herói não está acima das fraquezas humanas. Diante da doença, sofre e se ressente de si mesmo e da constatação de que talvez não haja um tratamento.

A emergência do câncer como uma nova ameaça de morte para o herói evidencia o caráter simbólico da doença e um imaginário que, embora ainda impregnado de associações às ideias de finitude e de sofrimento, está sujeito a constantes negociações e reformulações nas interações cotidianas e nas narrativas contemporâneas do eu. Conforme Lerner (2016):

A doença, ainda que adquira existência no corpo individual e tenha um fundamento biológico, é construída e partilhada socialmente. Ela torna-se inteligível a partir não apenas de um discurso médico-científico (que por sua vez já é uma construção sociocultural de um campo de saber instituído), mas também pela forma como ela está culturalmente apreendida numa dada sociedade (LERNER, 2015, p. 2).

O sofrimento do herói e a reação de seus companheiros, aliados, diante da doença corroboram tanto o estigma do câncer como o potencial de gerar empatia. O relato autobiográfico ou a narrativa do eu (SIQUEIRA, 2008; SIQUEIRA, FORTUNA, 2019) torna-se meio de expressão das emoções no imaginário dos quadrinhos nos quais nem os corpos superpoderosos dos heróis nem a ciência avançada são capazes de evitar a morte. A visão do corpo doente, mesmo antes de apresentar sinais físicos, é desconfortável e capaz de antecipar o sofrimento da morte. Ainda vivo, o corpo doente é encarado como em suspenso, um cadáver ambulante. 

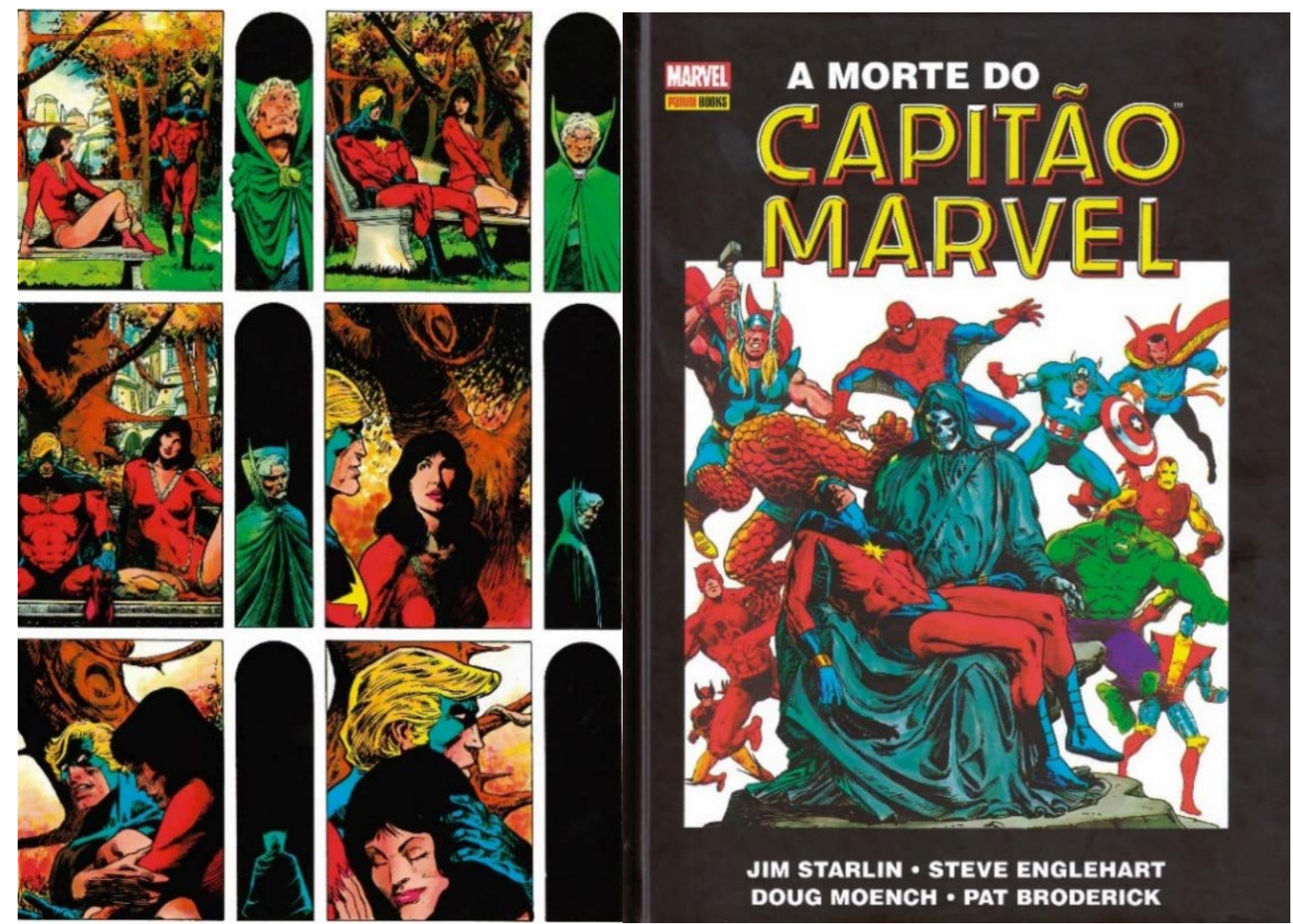

Figura 1 - A fatalidade da doença em imagens carregadas de emoções e as referências artísticas, como à Pietà, de Michelangelo

Fonte: Starlin, Englehart, Moench, Broderick (2017).

Ao longo da história, Mar-Vell é visitado por velhos amigos, como o personagem Rick Jones, que lutou ao seu lado, e pela namorada, Elysius, com quem vive uma das cenas mais fortes da narrativa. Sem diálogos, sem fazer uso da linguagem verbal, o autor narra o encontro dos dois personagens numa sequência apenas de imagens que vão da tranquilidade inicial de Elysius até o choro, quando ela, ao saber do diagnóstico, é confortada pelo herói. A sequência é intercalada com ilustrações (cenas) de Mentor, que os observa e, impotente, se afasta em direção às sombras. A narrativa fornece, na linguagem imagética e corporal dos personagens, o conteúdo dramático.

Embora, ao longo dos anos, outros personagens tenham enfrentado e vencido o câncer de formas muitas vezes fantásticas, a morte do Capitão Marvel alcançou notoriedade entre leitores e críticos pelo fato de não ter apresentado uma solução ‘mágica’ para o destino do herói. Após uma vida de grandes feitos e batalhas, a morte do herói, em decorrência do câncer, o humaniza e aproxima a narrativa do personagem da vida de um homem comum.

A história trouxe aos quadrinhos de heróis um tom solene ao tratar de temas como saúde, doença e morte. Embora atualmente diversos heróis da editora Marvel tenham morrido e ressuscitado, Mar-Vell, que morreu definitivamente, permanece entre as exceções, o que confirma o apelo de sua morte e a força narrativa do câncer como mediador de sentidos.

\section{A PAIXÃO DE JANE FOSTER}

Mas, se já não pode vencer e sobreviver, depende dele cumprir o que exige, a seus olhos como a de seus pares, sua condição de guerreiro: transformar sua morte em glória imperecível, fazer do lote comum a todas as criaturas sujeitas ao traspasso um bem que lhe seja próprio e cujo brilho seja eternamente seu (VERNANT, 1978, p. 31). 
Assim como a narrativa da morte de Mar-Vell, na qual o câncer aparece como substituto para a figura tradicional do supervilão, a saga de Jane Foster como Poderosa Thor serve de material para a discussão sobre o imperativo da medicina e sobre o câncer como experiência que modifica as relações entre indivíduos e sociedades. Embora trate de uma personagem de ficção, a história da Poderosa Thor a aproxima de narrativas de mulheres que "combatem" não somente o câncer mas, ao renunciarem a intervenções em seus corpos em decorrência do tratamento do câncer, como a reconstituição mamária, resistem à ideia de medicalização de sua existência e à aceitação passiva do estatuto de "vítimas".

Essas mulheres fazem de seus corpos signos de resistência, revertendo o estigma da doença e de suas consequências. Para elas, a cicatriz pós-cirúrgica torna-se um troféu, representação simbólica do seu encontro com a morte, que se reverteu a seu favor. A reconstituição da mama não substitui o órgão perdido, nem é vista como determinante para a manutenção da identidade feminina. Sua determinação em não permitir que estatutos vindos dos outros as concebam como "menos fêmeas", devido à perda de um órgão, lhes confere a condição singular de guerreiras ou “Amazonas" (LE BRETON, 2017, p. 206).

As semelhanças entre as histórias de Mar-Vell e de Jane Foster vão além da materialidade da doença. Nas narrativas, a emoção é elemento mediador e ambos têm que lidar com a frustração e revolta em relação ao corpo, lugar do adoecimento e da morte. Segundo Sontag (2007), o câncer foi por muitos anos carregado de metáforas e de uma aura de mistério, temido de modo tão agudo a ponto de ser considerado contagioso. A autora cita o medo de muitas pessoas de, somente, falar, enunciar o nome da doença. A ideia de doença 'maligna' dá ao câncer uma espécie de 'poder mágico', de maldição, de inimigo destruidor e invencível, e não a perspectiva de uma doença que pode ser tratada e até mesmo curada.

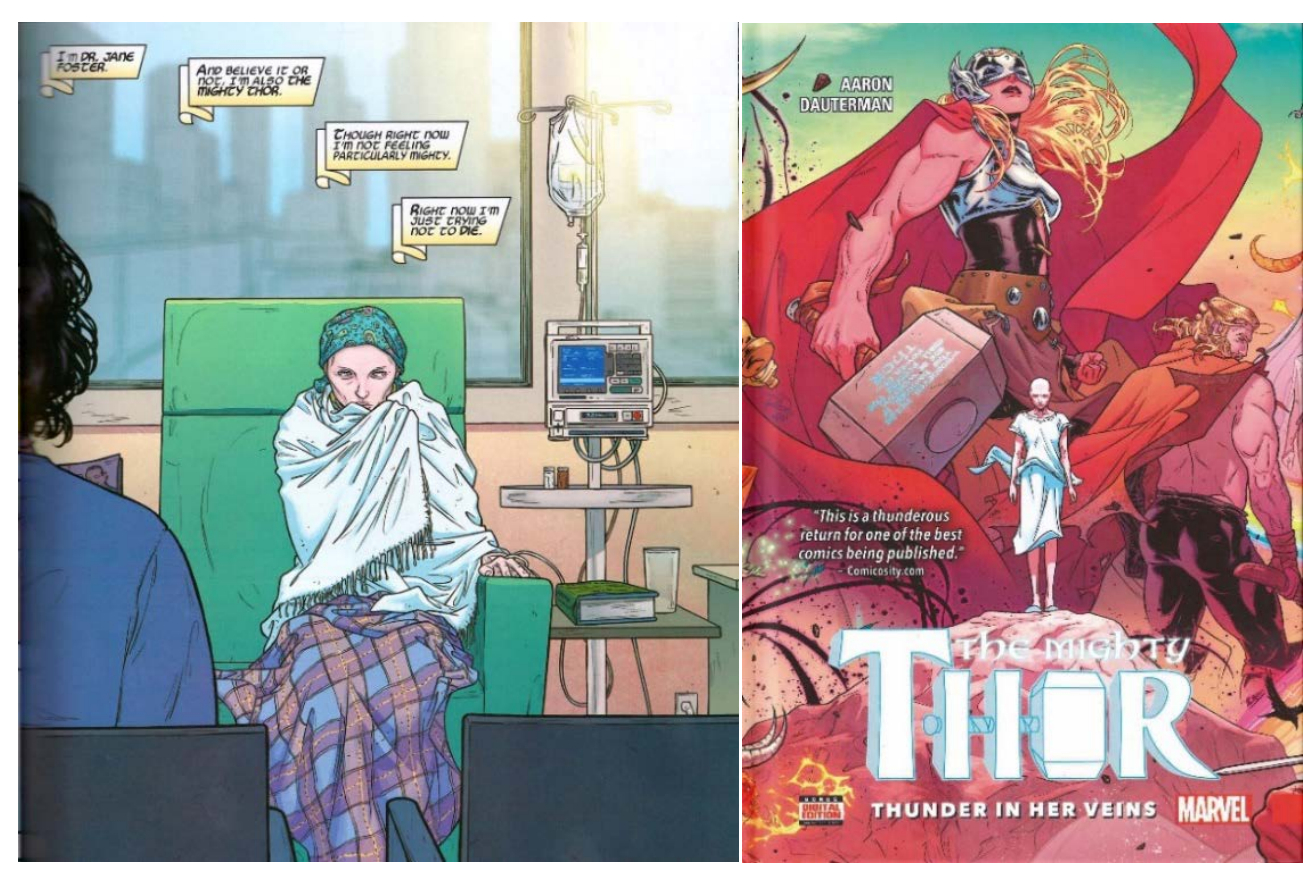

Figura 2 - A história de Jane Foster reforça as tensões entre o corpo mítico e o mortal Fonte: Aaron, Dauterman (2017).

Sontag destaca a ideia de traição pelo próprio corpo e do câncer como fonte de corrupção do caráter: "Mesmo que a doença não seja considerada um julgamento na comunidade, ela se torna um julgamento retroativamente - na medida em que põe em movimento um inexorável colapso da moral e dos costumes" (2007, p. 27).

A autora discute a relação romantizada da doença com a ideia de resignação: tanto o câncer poderia ser uma consequência dela, como uma causa. A doença como metáfora da morte passiva, inevitável, carrega 
em si o estigma de uma suposta sublimação dos sentimentos. Além disso, a imagem do câncer como sentença de morte afeta as relações e a vida sentimental dos doentes que, temendo o escândalo, a perda de relacionamentos ou empregos, assumem uma postura reservada (SIQUEIRA, 2015). O câncer não afeta apenas o corpo biológico, mas o sujeito como um todo, constituindo um elemento de ruptura e provocando um antes e um depois.

Como observou Michael Bury (1982), a representação da doença em seu caráter disruptivo, ou seja, de ruptura com a vida pregressa e de início de um novo período na vida do doente, caracteriza as narrativas de câncer - tanto nos relatos de pacientes como no drama dos personagens de quadrinhos. Bury analisa como doenças crônicas, a exemplo do câncer, constituem experiências que alteram as estruturas do cotidiano dos doentes. Segundo o autor, tais doenças promovem um reconhecimento da dor, do sofrimento e da ideia de morte, antes tidos como distantes ou destinados a outros sujeitos. A doença confronta o sujeito com a mortalidade e altera sua maneira de estar no mundo.

A impotência de heróis e deuses nas narrativas de Mar-Vell e Jane Foster caracteriza a força estéticoemocional do câncer. Edgar Morin (2009) ressalta o papel redentor da tragédia nas artes, a exemplo do teatro grego clássico, a partir do conceito de catarse, de Aristóteles, como forma de libertação ou purgação dos males. Para Morin, a simpatia em relação ao herói produziria uma forma de identificação pela qual seríamos capazes de transferir nossos sofrimentos para o herói que se dá em sacrifício, em uma forma de catarse pública. Na tragédia e morte do herói-deus experimentamos sua dor e suas aflições, mas também a redenção de nossas próprias falhas e paixões.

Um dos artifícios empregados para minimizar o impacto negativo da narrativa de doença nos quadrinhos é o uso da "bela morte" (VERNANT, 1978, p. 31), conceito utilizado por Vernant para descrever a morte gloriosa do herói. O grande êxito da bela morte não está em sobreviver, mas em fazer da sua queda um fato memorável e glorioso. A bela morte, na narrativa de câncer, reafirma questões morais relacionadas à doença, à culpa ('O que eu fiz para merecer isso?’) ou à moralização dos hábitos e costumes ('Se eu levar uma vida controlada, livre de riscos, terei mais saúde?’). Ela também promove a elevação moral do doente ao patamar de herói de sua própria história que, registrada, torna-se um bem comum, um benefício trazido à coletividade após a vitória ou morte gloriosa.

De forma semelhante às encenações do teatro clássico, a midiatização dos conflitos e das tragédias do herói fornece material simbólico para a construção de representações e de metáforas a partir das quais a sociedade projeta seus próprios conflitos e interesses, purgando-os na encenação da narrativa fantástica. A dramatização midiática da vida de heróis e de seus alter egos permitiria um sentir em comum, um partilhar, por meio de suas dores e sofrimentos.

Lowenberg e Davis (1994) discutem o conceito de medicalização e a interferência da medicina em cada vez mais áreas, inclusive no livre arbítrio e na tomada de decisão por parte dos pacientes. Os autores destacam algumas obras de ficção - Admirável mundo novo, de Huxley; 1984, de Orwell; e Laranja mecânica, de Burgess - como exemplos de representações das tiranias terapêuticas "[...] managed by coldly calculating, white-coated scientists in the act of bending hapless subjetcs to the purpose of a totalitarian state" (LOWENBERG; DAVIS, 1994, p. 580). Além disso, chamam atenção para projeções, na ficção científica, de visões de futuro em que a intrusão do modelo médico na liberdade de pensamento, na independência e na responsabilidade individual trazem graves consequências social e individualmente.

Na saga da Poderosa Thor, Jane é confrontada com o imperativo médico da saúde, sendo alertada por seus médicos e colegas sobre a necessidade de submeter-se ao tratamento, uma vez que seu corpo não se recupera. O que eles desconhecem, e que Jane narra em seus pensamentos, é o efeito da magia do martelo Mjolnir sobre seu corpo: 
I spent all morning in the hospital, injecting poison into my body, on purpose. Toxic chemicals designed to kill the cancer cells growing inside me. But as soon as I picked up the hammer... that was all for nothing. The transformation neutralizes the effects of the chemotherapy. It purges the poison from my body. But not the cancer. Because cancer is just another part of me now. A part that keeps getting bigger... and is killing me a little bit more... each time I change back. (AARON, 2017, p. 26).

O relato de Jane traz a tensão entre o corpo e as terapias de cura, muitas vezes tão dolorosas quanto a própria doença, e a revolta tanto em relação ao tratamento quanto ao próprio câncer, que ela não dissocia de seu corpo. A imagem que a heroína e seus pares fazem da doença, muitas vezes associada a imperativos morais - diante das ofertas da ciência médica, é moralmente correto que se cure -, reforça a tensão entre o saber arcaico (representado pela magia do martelo) e o científico: a transformação mística expulsa do corpo o 'veneno' da ciência, a quimioterapia; mas não o tumor, parte do próprio corpo. A escolha de Jane, de continuar lutando como Thor, apesar do risco para sua vida, mostra que, por mais que exista uma pressão externa ou interna para que se torne uma paciente disciplinada, resta a opção de negociar os termos da batalha. Como observa Le Breton,

L'existence sociale est faite d'une inépuisable série d'interprétations, de définitions de situations toujours remises sur le chantier. Entre le monde et l'homme il n'y a pas dualité, mais dialectique incessante, enchevêtrement. La pensée quand elle se dilue dans l'action est un processus symbolique qui transforme le monde en une matière de sens et de décision (LE BRETON, 2004, p. 47).

A imagem do doente, cuja aparência, por vezes debilitada, se opõe à imagem aceitável de saúde é, nas sociedades ocidentais, tão ou mais incômoda quanto a doença em si. Encarar o doente e a decadência de seu corpo é encarar a própria mortalidade. Muitas vezes, na busca de um culpado para uma visão tão ultrajante, diz-se que 'ele deve ter feito alguma coisa para merecer'. A culpa pode ser atribuída à falta de cuidado com a própria saúde ou por alguma falta cometida pelo doente ou por um manejo inadequado das emoções: 'ele deve ter guardado alguma mágoa'.

A visão da doença como punição por algum ato que ofenderia a moral é apontada nos estudos de Lowenberg e Davis (1994) com pacientes de serviços de terapias holísticas. Enquanto, de um lado, esse tipo de terapia procura uma desmedicalização na relação entre o profissional e o paciente, por outro, "[...] it can also be argued that the holistic views simultaneously emphasize a connectedness of self and environment, which again reinstates the self as central in the attribution of causality of illness" (LOWENBERG; DAVIS, 1994, p. 587). Essa visão daria ênfase a um sentido de causalidade que poderia levar pacientes a um sentimento de culpa, no caso de não terem seguido corretamente os hábitos de vida recomendáveis para a manutenção de uma boa saúde. A estigmatização resultante da culpa autoatribuída seria derivada de agentes externos, como os profissionais médicos mais tradicionais, a mídia e a própria literatura sobre medicina holística, interpretadas de maneira simplista ou equivocada.

Ao longo da saga, vemos o declínio físico de Jane, enquanto o mito da deusa do trovão se reforça, anunciando ao leitor uma provável morte gloriosa. Ao dirigir-se para a morte em batalha, na figura da Poderosa Thor, Jane inscreve-se na mitologia dos quadrinhos como a guerreira virtuosa capaz de proteger homens e deuses de ameaças terríveis. O conhecimento de que, ao retornar à forma humana, seu corpo sofre com o avanço da doença e a ineficácia do tratamento só a torna mais digna da dádiva final. 


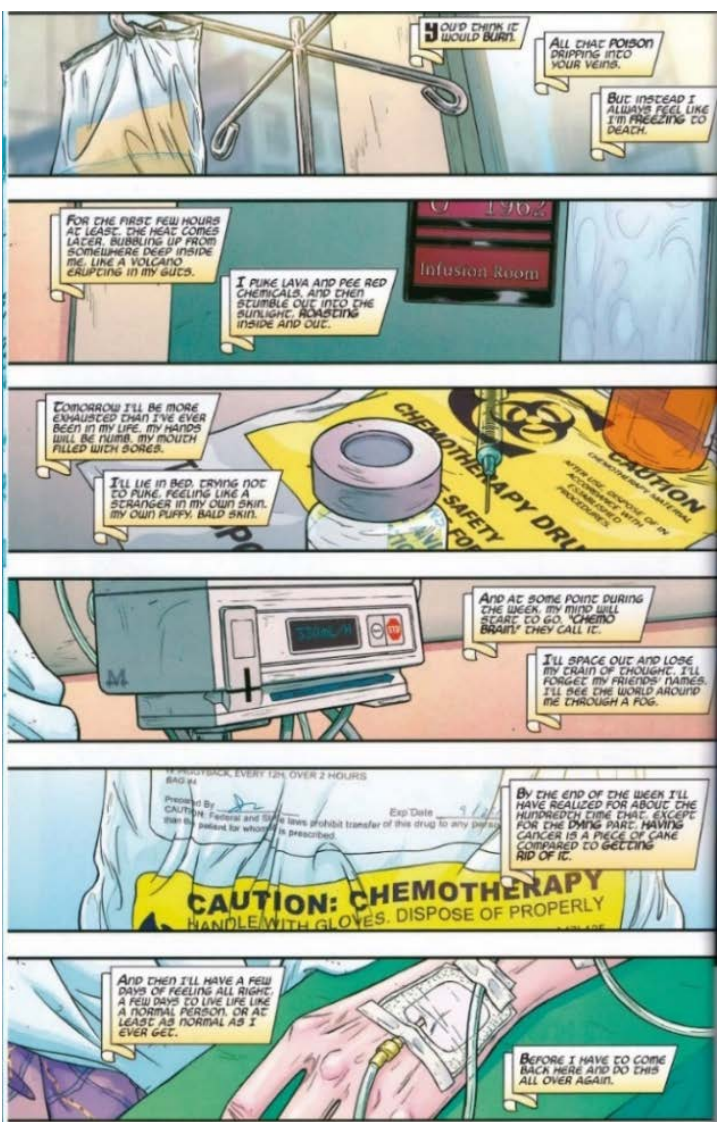

Figura 3 - A angústia da heroína e os sofrimentos decorrentes do tratamento Fonte: Aaron, Dauterman (2017).

Ao final da história, Jane é obrigada a enfrentar uma criatura destruidora de deuses que nem mesmo Odin é capaz de derrotar. A criatura virtualmente invencível, que faz tremer homens e deuses, parece um tipo de metáfora do câncer que, por muitos anos, foi visto como doença incurável e representada como um caranguejo monstruoso. Para salvar o povo de Asgard, a Poderosa Thor sacrifica o martelo Mjolnir, arremessando-o, junto com a criatura, ao Sol. Com a destruição do martelo, Jane retoma uma última vez sua moribunda forma humana e sucumbe à doença.

O drama da Poderosa Thor se encerra em batalha, com o sacrifício heroico que, na visão de Vernant (1978), citando as palavras do herói Heitor, na Ilíada, de Homero, caracteriza a bela morte: "não, eu não pretendo morrer sem luta e sem glória (akleiôs) como também sem algum feito cuja narrativa chegue aos homens por vir (essoménoisi puthesthai)" (VERNANT, 1978, p. 31). Vernant observa que a bela morte, nas orações atenienses, kalòs thánatos, relaciona ao herói caído em batalha a qualidade de "homem valoroso, homem devotado" VERNANT, 1978, p. 32). A essas qualidades somam-se o estado de glória, "e o fulgor dessa celebridade, kléos, que adere doravante ao seu nome e à sua pessoa, representa o termo último da honra, seu ápice, a areté realizada" VERNANT, 1978, p. 32).

Na história do Capitão Marvel, mesmo em seu leito de morte, em coma, o herói recebe a visita de seu maior adversário, o titã Thanos, que dá a ele uma morte grandiosa, em batalha. Na mente de Mar-Vell, o herói termina sua vida lutando contra seu mais poderoso inimigo, que o conduz ao além, entregando-o ao beijo da Morte. Mar-Vell, como Jane, tomba em batalha, reforçando o imaginário mítico e de combate à doença. A morte honrosa é o mínimo que se espera do herói.

Assim como 36 anos antes Mar-Vell expressara seu pesar e apego à vida, Jane, ao ver-se diante das portas do Valhalla, lugar mitológico para onde são levadas as almas dos heróis mortos em batalha, hesita, dizendo ainda não estar pronta. 
Life. Life is terrifying. And god-awful painful. And hard as all hell, even at the best of times. And this... This place feels like home. Like confort. So... Why can't I take that step? Why can't I let go of the pain? I guess... because... I know I had more to give. Because I wasn't done writing my story. (AARON, DAUUTERMAN, 2018, p. 180).

Em resposta ao questionamento da heroína e em reconhecimento por seu sacrifício, Odin e seu filho usam o poder da tempestade que dava vida ao martelo para ressuscitar Jane, concedendo-lhe, assim, uma segunda chance de enfrentar - e vencer - o maior dos inimigos: o câncer. Jane tem sua morte gloriosa, eukleès thanatós, revertida pelos deuses por mostrar-se novamente digna. Ao mesmo tempo, é possível imaginar que, ao negar a morte à heroína, Odin o faça não por bondade, mas para negar sua própria mortalidade. Pois, como afirma Elias (2011, p.11), "não é a morte, mas o conhecimento da morte que cria problemas para os seres humanos". Enquanto, para a Poderosa Thor, a narrativa é fechada, com início e final gloriosos, a de Jane Foster prossegue, dando a entender que a maior de suas batalhas, aquela contra o câncer, ainda está para ser travada.

\section{CONSIDERAÇÕES FINAIS}

Neste artigo tratamos de narrativas sobre o câncer no universo das HQs como forma de construção de sentidos e do imaginário sobre a doença. Por meio do estudo das histórias de adoecimento e morte da Poderosa Thor e do Capitão Marvel, elaboramos observações acerca da construção, nos comics, da relação entre os imperativos morais e o tema da bela morte. Abordamos questões relativas ao corpo e à experiência social do câncer e sobre a influência do saber médico na sociedade e na cultura das mídias.

Desde a morte do Capitão Marvel, em 1982, até a da Poderosa Thor, em 2018, o conhecimento científico trouxe avanços significativos no tratamento e detecção do câncer, bem como mudanças nas formas de conceber a doença, cujo forte apelo midiático contribuiu para sua emergência como assunto de "interesse comum" (LERNER, 2016, p. 41). Esse interesse fez com que autores de histórias em quadrinhos incluíssem o câncer na lista de 'vilões' e na construção das trajetórias de heróis. Em um universo mítico onde os próprios conceitos de vida e morte são flexíveis e no qual o corpo é palco da encenação de subjetividades e de relações de poder, o câncer emerge como ‘inimigo’ invencível, ameaçando a ideia de imortalidade e de superioridade física do herói. A abordagem da doença adiciona contornos à narrativa em que as emoções transbordam.

Lugar de construções simbólicas e de afetos, o corpo, como visto por Foucault (2018), emerge a partir do século XVIII como objeto de estudo das ciências biológicas e alvo de cuidados para um saber médico em formação. A partir da leitura de autores como Nikolas Rose (2007), discutimos a influência das práticas médicas na concepção das sociedades, das políticas de saúde e na própria forma do homem contemporâneo. Segundo Le Breton (2013), a exploração exaustiva, no discurso da comunicação, das técnicas e tecnologias de manipulação do corpo constitui meio de produção de identidades e de utopias do corpo. Finalmente, Lupton (2005) associa as práticas de controle social da doença e de seus riscos a valores e escolhas morais e a mecanismos de culpabilização.

A leitura das trajetórias da Poderosa Thor e do Capitão Marvel abre espaço para discussões sobre o papel do mito e sobre a influência do saber médico e científico no comportamento social. Elementos trazidos de narrativas de doentes de câncer e introduzidos no drama dos heróis reforçam o imaginário de sofrimento, medo e tragédia relacionado à doença. Ao promover uma ruptura na história pessoal dos personagens, o câncer põe em questão a ideia de mortalidade - mesmo em uma realidade fantástica onde a morte é reversível - e a influência dos saberes médicos, dos mitos e das representações na maneira de estar no mundo.

A trajetória do herói com câncer assemelha-se aos modelos e às representações midiáticas da doença. Assim como nas histórias de celebridades que enfrentam o câncer, nos quadrinhos o corpo é meio para a 
produção de sentidos e afetos. Afinal, como observa Siqueira, "o corpo, seus gestos e as palavras materializam a emoção" (2015, p. 17).

$\mathrm{Na}$ figura do herói que se sacrifica pelo bem da coletividade, fabricam-se modelos exemplares e de moralização dos costumes. Mesmo quando duvidam de si mesmos, Mar-Vell e Jane Foster colocam o bem comum acima de suas necessidades. Isso, no entanto, não os afasta das angústias do homem comum, do medo da morte, do sofrimento e da revolta contra o corpo, contra a ciência ou contra os deuses, nem da busca por uma bela morte.

A morte gloriosa do herói afigura, na narrativa mitológica, valores de honra e caráter, contribuindo para a construção moral da experiência do câncer. A negação da bela morte, na história da Poderosa Thor, ao dar à heroína uma segunda chance de buscar a cura, aponta para um julgamento moral, ligando a doença às questões de merecimento e ao estigma de castigo ou maldição. A narrativa midiática expressa anseios e busca redenção e fuga dos sofrimentos e das angústias da vida cotidiana, na figura do herói.

\section{REFERÊNCIAS}

AARON, Jason; DEODATO, Mike. Original Sin, n. 7, New York: Marvel Worldwide; 2014.

AARON, Jason; DAUTERMAN, Russell. The Mighty Thor Vol. 1: thunder in her veins. Nova York: Marvel Worldwide; 2017.

AARON, Jason; DAUTERMAN, Russell. The Mighty Thor Vol. 5: the death of the Mighty Thor. Nova York: Marvel Worldwide; 2018.BOZZ, Augusto Flamaryon Cecchin. Cartografias do câncer: biossociabilidade, comunicação e subjetividade. Dissertação (Mestrado em Comunicação) - Universidade Federal de Goiás, Goiânia, 2016.

BOZZ, Augusto Flamaryon Cecchin. Cartografias do câncer: biossociabilidade, comunicação e subjetividade. Dissertação (Mestrado em Comunicação) - Universidade Federal de Goiás, Goiânia, 2016.

BURY, Michael. Chronic illness as biographical disruption. Sociology of Health \& Illness, [s. I.], v. 4, n. 2, jul. 1982. DOI: https://doi.org/10.1111/1467-9566.ep11339939. Disponível em: https://pubmed.ncbi.nlm.nih. gov/10260456/. Acesso em: 4 jan. 2021.

CAMPBELL, Joseph. O herói de mil faces. São Paulo: Pensamento, 2007.

CONRAD, Peter. Medicalization and social control. Annual review of Sociology, [s. I.], v. 18, n. 1, p. 209-232, 1992. DOI: https://doi.org/10.1146/annurev.so.18.080192.001233. Disponível em: https://www.annualreviews. org/doi/abs/10.1146/annurev.so.18.080192.001233. Acesso em: 4 jan. 2021.

DOUGLAS, Mary. Pureza e perigo: ensaio sobre a noção de poluição e tabu. Lisboa: Edições 70, 1991.

ELIAS, Norbert. A solidão dos moribundos: seguido de "Envelhecer e morrer". Rio de Janeiro: Zahar, 2001.

FOUCAULT, Michel. Microfísica do poder. Rio de Janeiro: Paz e Terra, 2018.

LE BRETON, David. Adeus ao corpo: antropologia e sociedade. Campinas: Papirus, 2013.

LE BRETON, David. L'interactionnisme symbolique. Paris: Presses Universitaires de France, 2004.

LE BRETON, David. Un corps de résistance, un corps d'Amazone. Revue française de psychosomatique, Paris, n. 51, p. 195-212, 2017. DOI : https://doi.org/10.3917/rfps.051.0195. Disponível em: https://www.cairn. info/revue-francaise-de-psychosomatique-2017-1-page-195.htm. Consulta em: 17 jan. 2021.

LEE, Stan; LIEBER, Larry; KIRBY, Jack. Thor the Mighty and the Stone Men from Saturn!. Journey into Mystery, Nova York, v. 1, n. 83, p. 1-5, 1952. 
LERNER, Kátia. Doença, jornalismo e visibilidade: notas sobre a cobertura do câncer no jornal O Globo. Revista Communicare, São Paulo, v. 16, n. 1, p. 36-51, 2016. Disponível em: https://casperlibero.edu. br/wp-content/uploads/2016/12/Doen\%C3\%A7a-jornalismo-e-visibilidade-notas-sobre-a-cobertura-doc\%C3\%A2ncer-no-jornal-O-Globo.pdf. Acesso em: 4 jan. 2021.

LOWENBERG, June S; DAVIS, Fred. Beyond medicalization-demedicalization: the case of Holistic Health. Sociology of Health \& Illness, [s. I.], v. 16, n. 5, p. 579-599, 1994. DOI: https://doi.org/10.1111/1467-9566. ep11348024. Disponível em: https://onlinelibrary.wiley.com/doi/abs/10.1111/1467-9566.ep11348024. Acesso em: 4 jan. 2021.

LUPTON, Deborah. Risk: key ideas. New York: Routledge, 2005.

MAFFESOLI, Michel. Michel Maffesoli: o imaginário é uma realidade. Revista FAMECOS, Porto Alegre, v. 8, n. 15, p. 74-82, 10 abr. 2008. DOI: https://doi.org/10.15448/1980-3729.2001.15.3123. Disponível em: https:// revistaseletronicas.pucrs.br/ojs/index.php/revistafamecos/article/view/3123. Acesso em:

4 jan. 2021.

MAUSS, M. Sociologia e antropologia. São Paulo: Ubu Editora, 2017.

MORIN, Edgar. Cultura de massa no século XX: espírito do tempo. Rio de Janeiro: Forense Universitária, 2009.

ROSE, Nikolas. Beyond medicalization. The Lancet, [s. I.], v. 369, n. 9562, p. 700-702, 2007. DOI: https:// doi.org/10.1016/S0140-6736(07)60319-5. Disponível em: https://www.thelancet.com/journals/lancet/article/ PIIS0140-6736(07)60319-5/fulltext. Acesso em: 4 jan. 2021.

ROSENBERG, Charles E. Framing disease: illness, society and history. In: ROSENBERG, Charles E. Explaining epidemics and other studies in the history of medicine. Cambridge: Cambridge University Press, 1992. p. 305-318.

SIQUEIRA, Denise da Costa Oliveira. Comunicação e ciência: estudo de representações e outros pensamentos sobre mídia. Rio de Janeiro: EdUERJ, 2008.

SIQUEIRA, Denise da Costa Oliveira. Corpo, construção social das emoções e produção de sentidos na comunicação. In: SIQUEIRA, Denise da Costa Oliveira (org.) A construção social das emoções: corpo e produção de sentidos na comunicação. Porto Alegre: Sulina, 2015, p. 15-35.

SIQUEIRA, Denise da Costa Oliveira, FORTUNA, Danielle Ribeiro (orgs.). Narrativas do eu: gênero, emoções e produção de sentidos. Porto Alegre: Sulina; 2019.

SONTAG, Susan. A doença como metáfora. São Paulo: Companhia das Letras, 2007.

STARLIN, Jin; ENGLEHART, Steven; MOENCH, Doug; BRODERICK, Pat. A morte do Capitão Marvel. Barueri: Panini Brasil, 2017.

NATALIE Portman confirma detalhe importante do próximo filme de Thor. Terra, São Paulo, 10 out. 2020. Cinema. Disponível em: https://www.terra.com.br/diversao/cinema/natalie-portman-confirma-detalheimportante-do-proximo-filme-de-thor,d3e4ef108c21c160acd580cea789036b5dzmkgmr.html. Consulta em: 12 out. 2020 .

VERNANT, Jean-Pierre. A bela morte e o cadáver ultrajado. Discurso, São Paulo, n. 9, p. 31-62, 1978. DOI: 10.11606/issn.2318-8863.discurso.1978.37846. Disponível em: https://www.revistas.usp.br/discurso/article/ view/37846. Acesso em: 4 jan. 2021.

ZOLA, Irving Kenneth. Medicine as an institution of social control. The Sociological Review, [s. I.], v. 20, n. 4, p. 487-504, 1972. Disponível em: https://www.jstor.org/stable/43618673?seq=1. Acesso em: 4 jan. 2021. 